\title{
A snow and ice melt seasonal prediction modelling system for Alpine reservoirs
}

\author{
Kristian Förster $^{1,2}$, Felix Oesterle ${ }^{1}$, Florian Hanzer ${ }^{1,2}$, Johannes Schöber ${ }^{3}$, Matthias Huttenlau ${ }^{1}$, and \\ Ulrich Strasser ${ }^{1,2}$ \\ ${ }^{1}$ alpS - Centre for Climate Change Adaptation Innsbruck, Innsbruck, Austria \\ ${ }^{2}$ Institute of Geography, University of Innsbruck, Innsbruck, Austria \\ ${ }^{3}$ TIWAG, Tiroler Wasserkraft AG, Innsbruck, Austria \\ Correspondence to: Kristian Förster (kristian.foerster@uibk.ac.at) \\ Published: 17 October 2016
}

\begin{abstract}
The timing and the volume of snow and ice melt in Alpine catchments are crucial for management operations of reservoirs and hydropower generation. Moreover, a sustainable reservoir operation through reservoir storage and flow control as part of flood risk management is important for downstream communities. Forecast systems typically provide predictions for a few days in advance. Reservoir operators would benefit if lead times could be extended in order to optimise the reservoir management. Current seasonal prediction products such as the NCEP (National Centers for Environmental Prediction) Climate Forecast System version 2 (CFSv2) enable seasonal forecasts up to nine months in advance, with of course decreasing accuracy as lead-time increases.

We present a coupled seasonal prediction modelling system that runs at monthly time steps for a small catchment in the Austrian Alps (Gepatschalm). Meteorological forecasts are obtained from the CFSv2 model. Subsequently, these data are downscaled to the Alpine Water balance And Runoff Estimation model AWARE running at monthly time step. Initial conditions are obtained using the physically based, hydro-climatological snow model AMUNDSEN that predicts hourly fields of snow water equivalent and snowmelt at a regular grid with $50 \mathrm{~m} \mathrm{spac}$ ing. Reservoir inflow is calculated taking into account various runs of the CFSv2 model. These simulations are compared with observed inflow volumes for the melting and accumulation period 2015.
\end{abstract}

\section{Introduction}

Hydropower is a major contributor to carbon-free energy production in the European Alps where ideal conditions for this type of energy production prevail (Schaefli, 2015). In general, mountainous regions are subjected to strong altitudinal gradients, which is important for efficient hydropower production. Moreover, mountain ridges induce orographic lifting of air masses causing higher precipitation depths than in surrounding lowland regions (Koboltschnig and Schöner, 2011). Snow and ice are accumulated and seasonally released as melt water in spring and summer making mountainous headwaters very important for hydrological regimes of various European rivers and thus for hydropower as well (Viviroli et al., 2007).
Reservoirs are not only relevant for hydropower generation but also for flood control and water supply. Thus, hydropower management depends on various factors that need to be addressed in day-by-day operation. Typically, longterm observations and short-term meteorological and hydrological predictions serve as a basis for this task. However, predicting several components of the water balance components at various spatial and temporal scales is challenging in this environment as meteorological fields such as temperature or precipitation greatly vary in space and time, even at short time scales (Klemeš, 1990).

In general, two types of seasonal prediction strategies are available for hydrologic applications (Yuan et al., 2015): On one hand, common methods in hydrology are based on the Ensemble Seasonal Prediction, building upon procedures which resample historical meteorological data. This method 
is well suited where initial conditions can be seen as a "land surface memory" that last over a certain time period (Yuan et al., 2015). On the other hand, climate models based on (dynamical) seasonal methodology rely on physical modelling of the coupled atmosphere-ocean system. This is important as atmosphere-ocean systems interact at a broad range of scales, influenced by sea surface temperature anomalies as well as associated surface air pressure fields such as El Niño Southern Oscillation (ENSO) or the North Atlantic Oscillation (NAO), and their atmospheric teleconnections strongly affect weather patterns at smaller scales (Doblas-Reyes et al., 2013). The pioneering work of (Wood et al., 2002) showed the applicability of dynamical seasonal prediction systems in principle. The recently released Climate Forecast System version 2 (Saha et al., 2014), fulfilling all requirements for seasonal initial value based predictions as claimed by (Kanamitsu et al., 2002), provides seasonal forecasts every $6 \mathrm{~h}$ operationally. Data is available online and its capabilities for hydrological applications are considered as promising (Yuan et al., 2011). The physical basis as well as the availability of data makes CFSv2 an interesting source of information about anomalies of meteorological variables for the next few months even if the spatial resolution is comparatively coarse and the predictive accuracy decreases with increasing lead times. In the framework of this paper, first results of CFSv2 forecasts for a small catchment in Tyrol/Austria (Gepatschalm) are presented. A simple statistical downscaling approach is applied in order to scale gridded monthly averages of temperature and precipitation to monthly station recordings. Then, a water balance model with snow and ice melt capabilities that has been designed for this task is calibrated and validated for different periods of time using reanalysis data of the climate model. Finally, first results of the melting season 2015 and the following accumulation season are presented.

\section{Study area}

In order to test the applicability of seasonal predictions for small meso-scale catchments relevant for hydropower generation, the Gepatschalm catchment $\left(55 \mathrm{~km}^{2}\right)$ has been selected. It represents a typical high altitude Alpine catchment with an altitudinal range between 1895 and $3504 \mathrm{~m}$ a.s.l. The latter value is close to the altitude of the highest summit of the Ötztal Alps, the Wildspitze (3770 m a.s.1.). Approximately $37 \%$ of the area is covered by glaciers, according to the 3rd Austrian Glacier Inventory updated in 2006 (Fischer et al., 2015). Moreover, downstream of the Gepatschalm gauge a reservoir was built and completed in 1964. The reservoir capacity is 139 million $\mathrm{m}^{3}$; it has been designed for additional inflow of several catchments in the vicinity that are diverted to the reservoir. Here, the natural catchment area is investigated (Fig. 1).

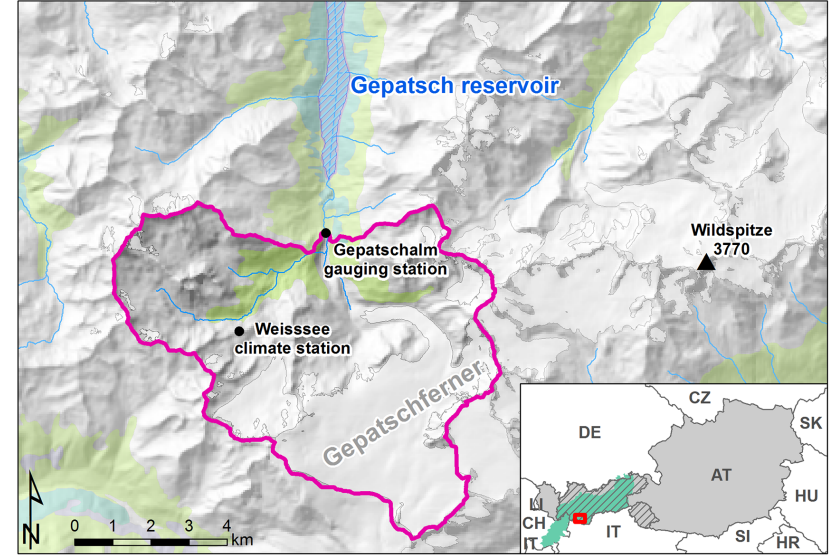

Figure 1. Map showing the study area located in Tyrol/Austria (hatched area in the small map) including the Gepatschalm catchment upstream of the Gepatsch reservoir. The Gepatschferner is the largest glacier in Western Austria (glaciers in light grey). The Inn river catchment is highlighted in green in the small map.

The runoff as recorded by the Gepatschalm gauge since 1983 is strongly influenced by seasonal effects as snow and ice melt runoff dominates in late spring and summer resulting in mean monthly runoff depths greater $500 \mathrm{~mm}$ whereas the winter runoff is very low (less than $10 \mathrm{~mm}$ per month). According to the Austrian Glacier Inventory, the Gepatschferner - the largest glacier of the study region - covered $16.6 \mathrm{~km}^{2}$ in 2006. At present, glaciers undergo a rapid decline both in the study area and worldwide (Fischer et al., 2015; Marzeion et al., 2014). For long-term investigation, the areal glacier extent has to be continuously updated in order to incorporate the variable surface ice melt areas (Schueller et al., 2015).

\section{Set-up of seasonal forecasts and water balance simulations}

\subsection{The CFSv2 model and linear regression downscaling}

The NCEP Climate Forecast System version 2 (CFSv2) has been developed at the Environmental Modeling Center at the National Centers for Environmental Prediction (NCEP). Since 2011, the model has been made operational. The model software, all relevant data and the seasonal forecasts are available to the public (see, e.g., http://cfs.ncep.noaa.gov/). Computations are performed on a horizontal grid with a resolution of roughly $100 \mathrm{~km}$ and 64 vertical levels of the atmosphere (Saha et al., 2014). Besides the atmospheric model, CFSv2 also includes a land surface, cryosphere and ocean model. These model components are coupled in order to adequately describe interactions among the systems described by each of these sub-models. A detailed description of the model dynamics and physics is provided by Saha et al. (2014). For practical purposes in the framework 
(a)

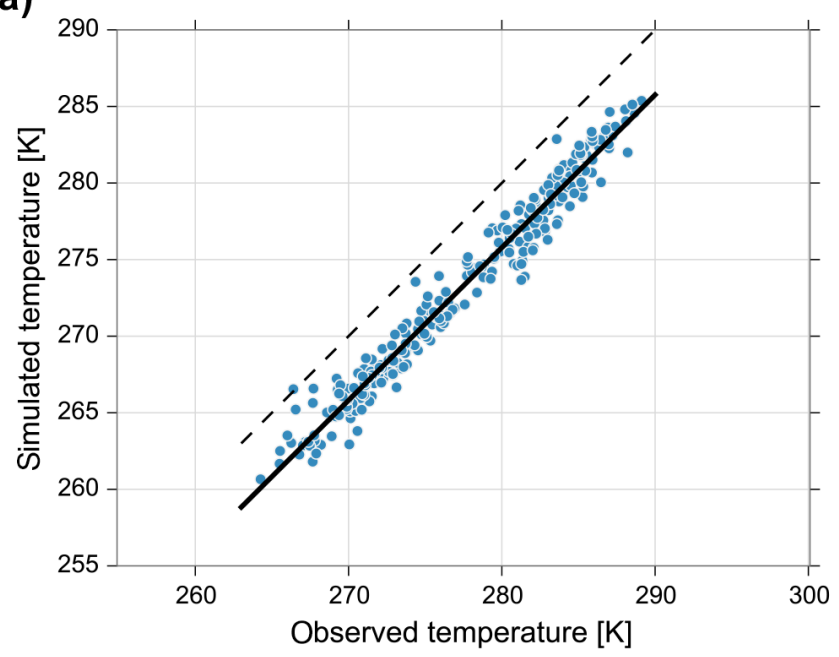

(b)

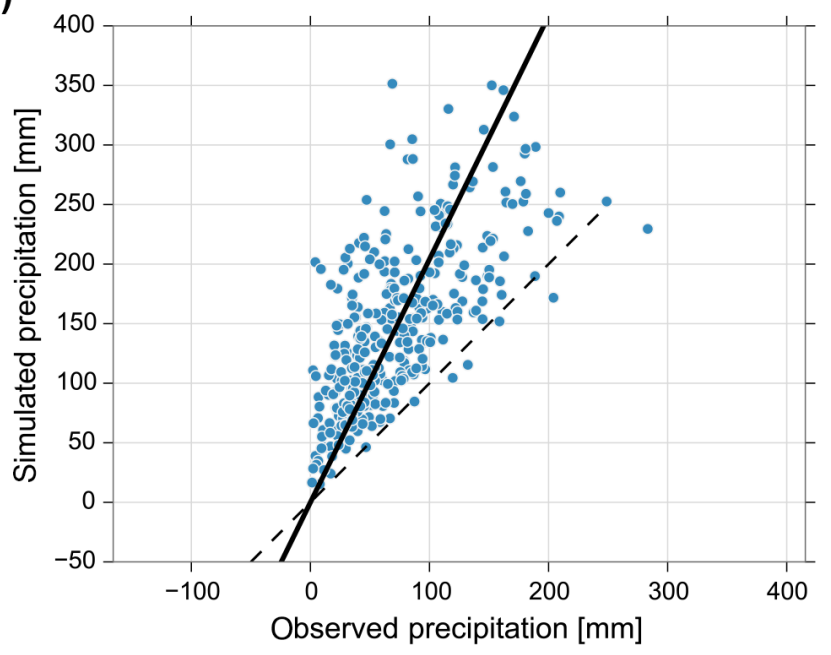

Figure 2. Scatter plots of modelled vs. observed temperature (a) and precipitation (b). Each point represents the mean temperature and the precipitation depth of one month in the period 1986-2009, respectively. Besides the diagonal line (dashed), the regression line is also added to each plot (solid).

of this study, we focus on some features that are relevant for hydrological modelling.

CFSv2 is run 4 times a day performing simulations for the next 9 months. Additionally, a re-analysis dataset ranging from 1979-2014 is available. In order to assess the applicability of CFSv2 data for the study area, monthly time series of temperature and precipitation extracted from the re-analysis dataset have been compared to observations recorded by a meteorological station. For investigating the Gepatschalm catchment in this context, the nearest meteorological station that provides long-term recording is located in the vicinity of the dam of the Gepatsch Reservoir (approx. $7 \mathrm{~km}$ north of the gauge). Long-term time series are needed as a sound database for model evaluations, also with respect to sub-sequent bias corrections.

Figure 2 shows scatter plots for temperature and precipitation with modelled values plotted against observations. Each point represents one month within the period 1986-2009. Mean monthly temperature coincides well with observation. A cold bias yielding approximately $-3.4 \mathrm{~K}$ can be observed from the plot in Fig. 2a. For the subsequent simulations, the respective slope and intercept parameter derived from regression analyses are applied in order to linearly adjust the underestimation of temperature for the study area. This procedure can be seen as a simple bias correction method $\left(R^{2}=0.97\right)$. The modelled monthly precipitation depth is on average twice the value obtained through long-term records. Instead of using a linear regression, a pure multiplicative correction (Kuentz et al., 2015) is used instead without assuming an intercept parameter that might yield negative values in the transformation procedure $\left(R^{2}=0.47\right.$, Fig. $\left.2 \mathrm{~b}\right)$. Time series of shortwave radiation are also derived from the CFSv2 data. Other than temperature and precipitation, shortwave radiation recordings are only available as of 2011 . Since reanalysis data are available until 2014, at least three years of both observed and modelled values are directly comparable (see Fig. 3). CFSv2 tracks the seasonal characteristics very well. However, shortwave radiation is overestimated during the summer months. Due to the short overlapping period that covers both observed and modelled values, monthly mean shortwave radiation time series are used "as is" in this study as the number of values is too small for statistical corrections. Instead, overestimation of shortwave radiation is compensated through calibration of the water balance model as described in the next section. This approach is seen as feasible method to compensate for model biases since the melt computations include an adjustable radiation dependent melt factor. Thus, the radiation biases are corrected through model calibration in this study.

\subsection{The water balance model AWARE and its application}

Nowadays, hydrological models typically operate at one hour or one day time steps. For flood forecasting, hourly time steps are typical, whereas in urban hydrology, even smaller time steps are employed. For monthly time series of input data, these models cannot be applied without utilising further temporal disaggregation techniques, which scale monthly values to smaller time steps. For instance, (Wood et al., 2002) propose a scaling of historical daily time series so that these time series match the respective monthly means of the forecast. Another possibility is to revisit water balance models that operate at one month time steps (McCabe and Markstrom, 2007), which might be seen as feasible approach given that 


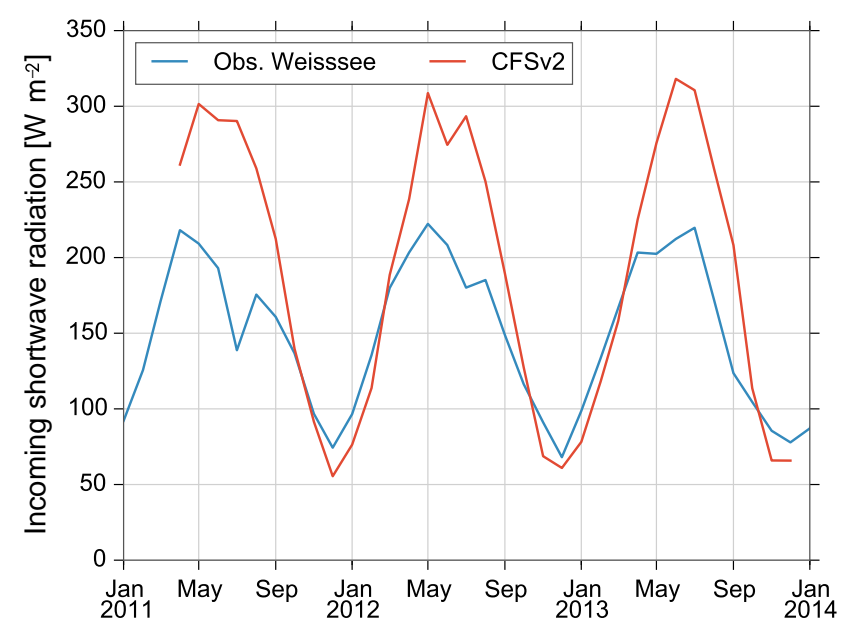

Figure 3. Modelled and observed shortwave radiation. Observations have been recorded at the Weisssee climate station ( 2480 m a.s.l., see Fig. 1), whereas modelled values are derived from CFSv2 without any modification.

seasonal forecasts address anomalies rather than predicting the weather of specific days. In this study, the latter methodology is pursued for practical reasons.

Here, a simple water balance model ("AWARE": Alpine Water balance And Runoff Estimation model) has been developed including all relevant processes for the study area. The model design also addresses initialisation of system states through other models operating operationally. The physically-based hydro-climatological model AMUNDSEN (Strasser, 2008; Strasser et al., 2011), running at hourly time step, is used to derive snow water equivalent (SWE) maps using $50 \mathrm{~m}$ grid spacing in operational mode for the Inn River catchment in Tyrol and adjacent regions (green area in the small map of Fig. 1). In order to employ areal SWE maps as initial conditions for the water balance model with meteorological forcing using CFSv2, the water balance model is a distributed model and has been designed to be capable of running on the same grids as AMUNDSEN.

The water balance model includes 5 different process modules: (i) meteorological pre-processing, (ii) snow and ice melt, (iii) evapotranspiration, (iv) soil water balance, and (v) groundwater. In order to account for lower temperatures and higher precipitation totals at higher altitudes, empirical gradients for temperature and precipitation are applied to the meteorological input downscaled for the meteorological station situated close to the Gepatsch reservoir. The methodology and parameters are similar to the ones in AMUNDSEN. Snow and ice melt are calculated separately assuming different parameterisations of the enhanced degree day method which also incorporates radiation (Hock, 1999), which is crucial for snow and ice melt. In contrast to the cited study that considers hourly melt rates, the proposed methodology is applied to monthly averages of temperature and radiation.
Table 1. Model performance measures for the water balance model AWARE forced by CFSv2 re-analysis data. NSE $=$ NashSutcliffe model efficiency, PBIAS $=$ Percent Bias, RMSE $=$ Root Mean Square Error, RSR $=$ RMSE observations standard deviation ratio, $R=$ Pearson's correlation coefficient.

\begin{tabular}{|c|c|c|}
\hline Performance measure & $\begin{array}{r}\text { Calibration } \\
(1995-2009)\end{array}$ & $\begin{array}{r}\text { Validation } \\
(1985-1992)\end{array}$ \\
\hline Number of months [-] & 180 & 96 \\
\hline NSE $[-]$ & 0.78 & 0.76 \\
\hline PBIAS [\%] & -23.67 & -5.83 \\
\hline RMSE [mm month $\left.{ }^{-1}\right]$ & 79.43 & 90.36 \\
\hline $\operatorname{RSR}[-]$ & 0.47 & 0.49 \\
\hline$R[-]$ & 0.91 & 0.87 \\
\hline
\end{tabular}

This is viewed as an adequate adaptation since the original degree day method can be also reliably applied using average monthly degree day values (Rango and Martinec, 1995). Evapotranspiration is computed according to the (Thornthwaite, 1948) approach. Water fluxes associated with the soil water balance are approximated according to (McCabe and Markstrom, 2007). A linear storage is implemented to account for the groundwater storage and low flow recession.

A split sample test was applied in order to calibrate and validate the model using different periods of time (Klemeš, 1986) as shown in Fig. 4. The period 1995-2009 was used for calibration, while the period 1985-1992 was used for validation (due to some missing values in the CFSv2 re-analyses data, the years 1993-1994 were not considered). Table 1 summarises the calibration and validation period for the water balance model driven by CFSv2 re-analyses. To quantify the deviations between model and observations, a set of performance measures were calculated (Moriasi et al., 2007): Nash-Sutcliffe model efficiency (NSE) values between 0.65 and 0.75 are viewed as "good" model performance rating for monthly time steps. Hence, the NSE value achieved for the calibration period is within the range of "good" values whereas the respective value of the validation period is even "very good" according to this categorisation. These findings also hold true for the RMSE observations standard deviation ratio (RSR). For the percent bias the achieved results fall into the category "satisfactory" (calibration period) and "very good" (validation period) indicating smaller differences between modelled and observed runoff volume in the validation period. However, the modelled peak melt runoff is underestimated in some cases even though modelled runoff is on average slightly higher compared to the observations. In contrast, the model overestimates low flow during the winter months. Notwithstanding these uncertainties in model skill, the modelled time series tracks the observations well. Thus, it is assumed that the model is capable of transforming seasonal predictions of meteorological fields to corresponding runoff and SWE predictions for the study area. 


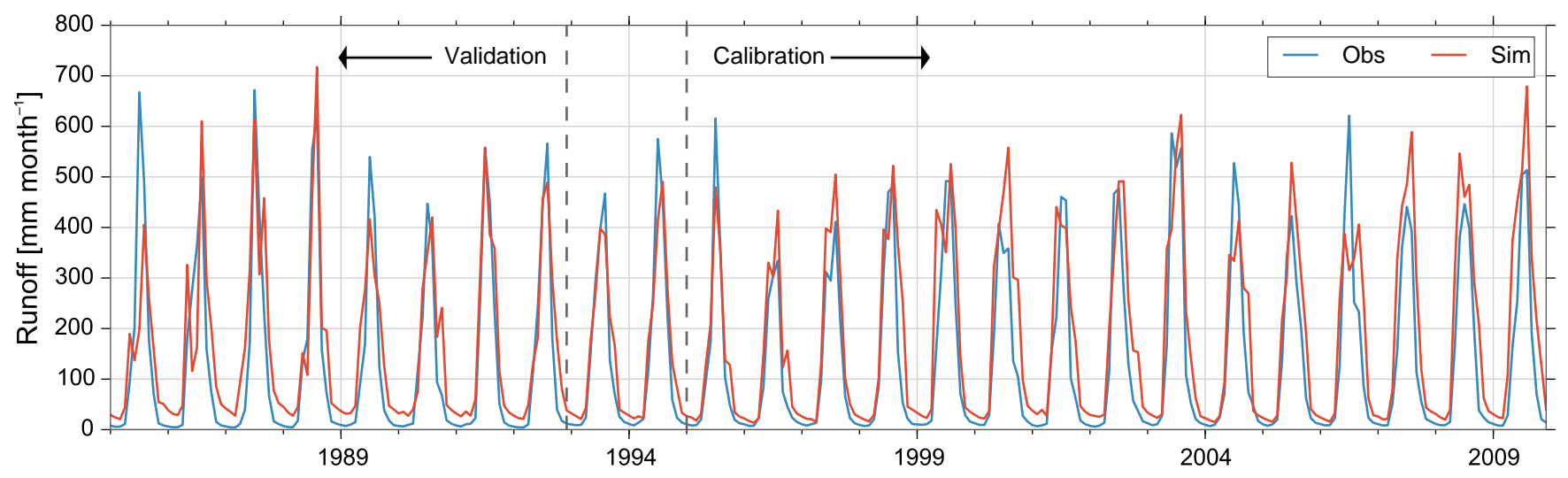

Figure 4. Time series of observed (blue line) and modelled runoff (red line) calculated using the water balance model AWARE forced by CFSv2 data.

\section{Results and discussion}

Test operation of the water balance model for seasonal prediction using CFSv2 data has been started in early summer 2015. As initial conditions are crucial for seasonal predictions, appropriate initial states for the most important hydrological storages need to be prepared prior to the model runs. For mountainous and sub-arctic catchments, SWE is the most important variable that needs to be initialised in order to accurately predict snowmelt. Operational snow maps obtained by AMUNDSEN are used as initial conditions in each seasonal forecast run of the water balance model (for an example see Fig. 5). SWE reaches up to several hundred millimetres at the beginning of June 2015. Snow free conditions can be observed in the lower elevation bands, whereas SWE is highest on the glaciers.

Figure 6 shows the first results of the water balance model in forecast mode. Seasonal forecasts performed by CFSv2 were prepared for one day each in June, July, and August 2015. The correction methods derived by evaluating the reanalysis data were applied in order to account for systematic errors in the forecasts likewise. The range of catchmentscale SWE values (average of all grid cells) derived by different ensemble members is subjected to small variations in autumn. Beyond mid-winter, the results indicate a large variety of possible SWE evolutions. A peak accumulation in May 2016 yielding a similar areal SWE is just as possible as a total melt. The first case indicates average conditions whereas the latter case can be viewed as a winter with little snowfall.

The runoff depth as modelled by the water balance model is of the same order of magnitude as the values recently observed in July, August and September 2015. For instance, the runoff time series of the run initialised in June distinctively overestimate observations in the first month of the simulation (precipitation input $240 \mathrm{~mm} \mathrm{month}^{-1}$ ) whereas the value predicted for July 2015 is smaller than the corresponding observation. From August 2015, simulated runoff depths are overestimated compared to observations. This finding also holds

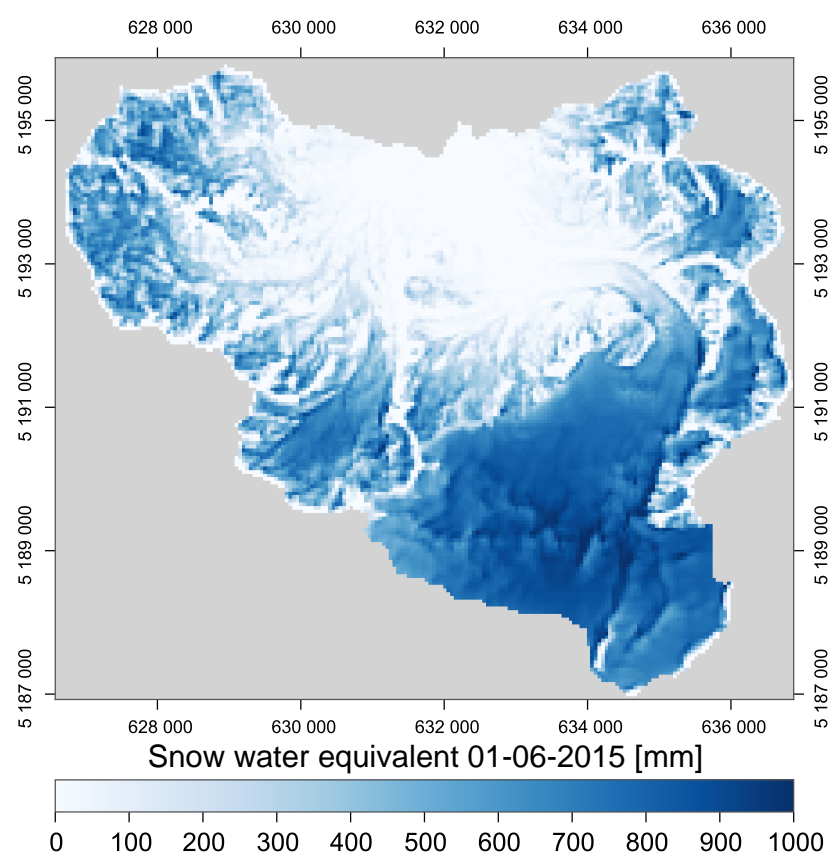

Figure 5. Areal initial values of snow water equivalent (SWE) provided by AMUNDSEN for 1 June 2015.

true for the runs initialised in July and August. However, the range of values derived by four independent initialisations of the CFSv2 is large as it covers values from approx. 200 to $1000 \mathrm{~mm} \mathrm{month}^{-1}$. In contrast, the ensemble mean represents typical values observed for August. The bandwidth of values derived by ensemble runs decreases in autumn and winter as melt diminishes and precipitation falls mainly as snow merely contributing to an increase in SWE. In June and August 2015, the overestimation of runoff depth in some runs can be addressed to exceptionally high precipitation depths computed by CFSv2. 

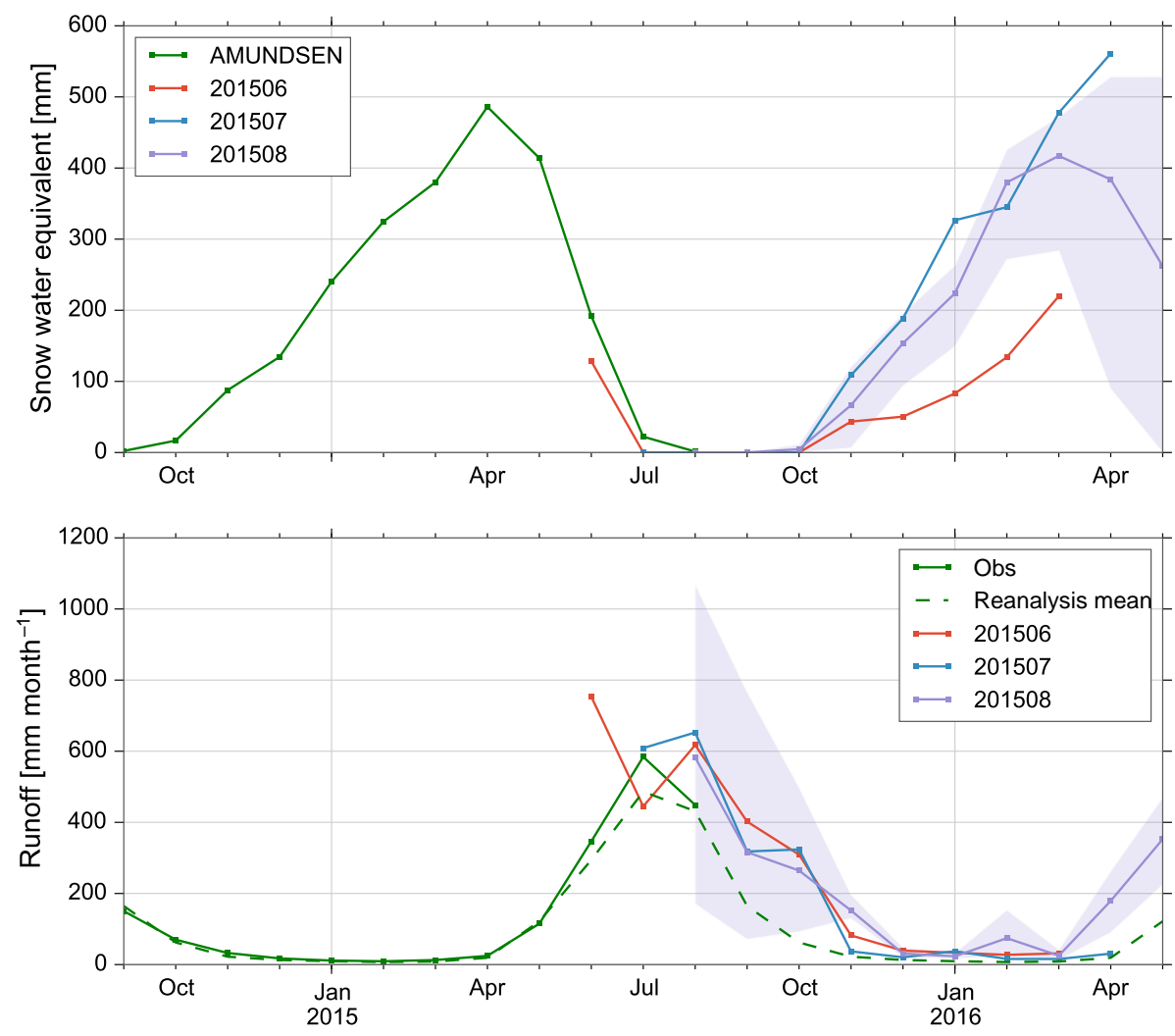

Figure 6. Seasonal forecasts of SWE (top) and runoff (bottom) using the water balance model AWARE, initialised by AMUNDSEN and forced by CFSv2. In addition to the ensemble mean, the range of results achieved by four CFSv2 runs in August 2015 is shown as shaded area. The dashed green line indicates average runoff conditions computed using re-analysis data (1985-2009).

When considering the entire simulation period, differences in total precipitation depth among the ensemble members are relevant for seasonal snow accumulations as well. For instance, a total precipitation depth of $710 \mathrm{~mm}$ is predicted for the period August 2015-May 2016 if the run initialised on 10 August 2015 at 06:00 z (06:00 UTC) is considered. In contrast, the same evaluation applied to the run initialised at $18: 00 \mathrm{z}$ on the same day yields $980 \mathrm{~mm}$ (see Fig. 7).

Apart from the run initialised in June, runs that are initialised in consecutive months coincide reasonably with recent observations, at least for one or two months. The differences between two consecutive runs are small for up to three months in advance. However, if single ensemble runs are compared with each other, a large range of forecasted runoff depths in summer and SWE in winter and spring is obvious.

\section{Conclusions and outlook}

The present study analyses available CFSv2 forecasts for runoff and SWE in a meso-scale Alpine catchment and hence, represents a first assessment of feasibility. The results obtained by the water balance model, which is forced using CFSv2 data, are promising with respect to future ap- plications of seasonal forecasts in the study area. The presented results indicate that the model system as yet applied to a glaciated catchment - provides useful results for lead times up to three months. In this snow accumulation and melt dominated catchment, increased uncertainties regarding SWE and runoff appear as the superposition of the uncertain precipitation and temperature inputs for lead times larger than three months. However, if the positive trend of results for lead times up to approximately 100 days could be verified in further model tests, such a model system could support the day-by-day operation as water management tool for hydropower companies. Therefore, an operational use of the model chain CFSv2 $\rightarrow$ AWARE is pursued to provide estimates of runoff for the upcoming one to three months. In this way, seasonal predictions complement the already existing flood forecasting system for the Inn River called HoPI "Hochwasserprognose für den Tiroler Inn" (Achleitner et al., 2012; Huttenlau et al., 2016).

Further evaluations of the forecast data and subsequent water balance simulations for the study area are still needed to understand possible uncertainties in seasonal forecasts. For instance, the relatively high precipitation depth values achieved by runs in June and August 2015 resulted in model overestimation with respect to runoff. Moreover, SWE evo- 
(a) 2015-08, init: $06 z$

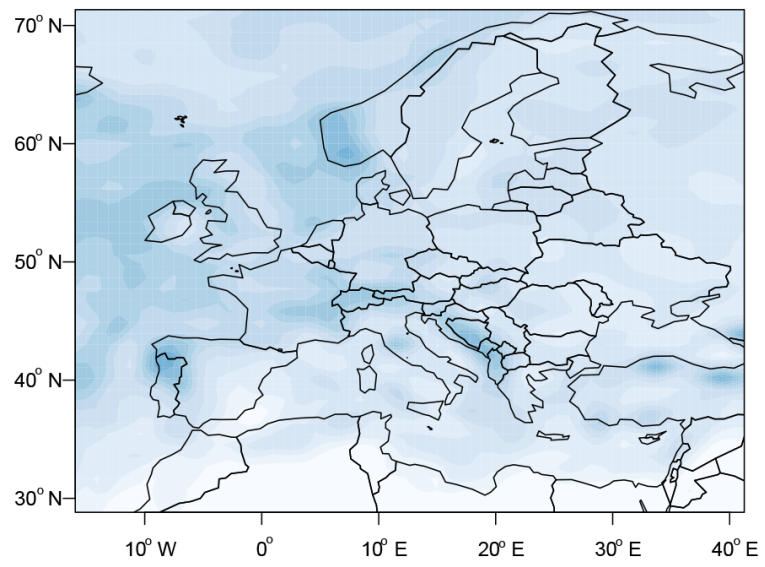

(b) 2015-08, init: $18 z$

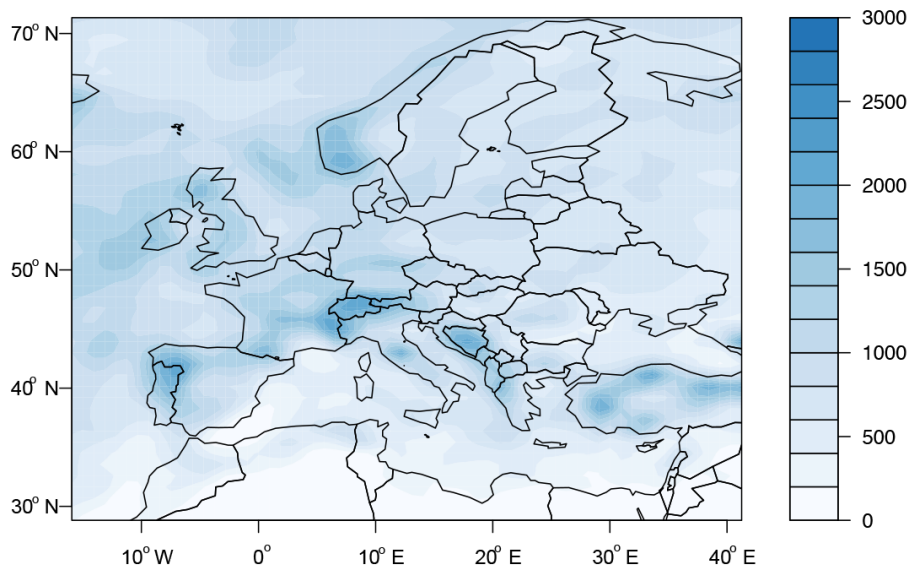

Figure 7. Areal distribution of precipitation depth in mm for the period August 2015-May 2016 as predicted on 10 August 2015 by two CFSv2 runs initialised at (a) 06:00 $\mathrm{z}$ and (b) 18:00 z, respectively.

lution in the subsequent winter season strongly depends on seasonal precipitation depth. To address these issues, a systematic evaluation of forecast data is foreseen in order to achieve quantitative information about the accuracy of the forecasts in the study area, i.e. by gathering forecasts (ensembles) throughout several months (years) in order to relate uncertainties in predictions to observations. Then, Model Output Statistics (MOS) (Warner, 2011) might be also beneficial to improve forecasts by means of correction approaches that rely on previous forecasts and observations. Therefore, the application of ensemble runs need to be performed more rigorously to gain insight into uncertainties and to provide probability frameworks. Besides methodological enhancements, extensions to the study area are also foreseen to incorporate catchment areas that are artificially drained to the Gepatsch Reservoir.

\section{Data availability}

Both re-analysis data as well as operational forecasts of the CFSv2 model are available for free. CFSv2 re-analysis data (Saha et al., 2010): http://cfs.ncep.noaa.gov/pub/raid0/cfsv2/ climo_cfsr_month/flxf06/

Operational CFSv2 7 Day Rotating Archive (Saha et al., 2014): http://nomads.ncep.noaa.gov/pub/data/nccf/com/ $\mathrm{cfs} / \mathrm{prod} / \mathrm{cfs} /$

Acknowledgements. This work was carried out as part of the project "W01 MUSICALS II - Multiscale Snow/Ice Melt Discharge Simulation for Alpine Reservoirs" at alpS - Centre for Climate Change Adaptation in Innsbruck, Austria. The K1-Centre alpS is funded through the Federal Ministry of Transport, Innovation and Technology (BMVIT), the Federal Ministry of Science, Research and Economy (BMWFW), as well as the Austrian Provinces of the Tyrol and Vorarlberg within the scope of COMET - Competence
Centers for Excellent Technologies. The Programme COMET is managed by the Austrian Research Promotion Agency (FFG). We want to thank TIWAG - Tiroler Wasserkraft AG for the collaboration and co-funding the project, as well as the Editor W. Grabs for his valuable comments.

\section{References}

Achleitner, S., Schöber, J., Rinderer, M., Leonhardt, G., Schöberl, F., Kirnbauer, R., and Schönlaub, H.: Analyzing the operational performance of the hydrological models in an alpine flood forecasting system, J. Hydrol., 412-413, 90-100, doi:10.1016/j.jhydrol.2011.07.047, 2012.

Doblas-Reyes, F. J., García-Serrano, J., Lienert, F., Biescas, A. P., and Rodrigues, L. R. L.: Seasonal climate predictability and forecasting: Status and prospects, WIREs Clim Change, 4, 245-268, doi:10.1002/wcc.217, 2013.

Fischer, A., Seiser, B., Stocker Waldhuber, M., Mitterer, C., and Abermann, J.: Tracing glacier changes in Austria from the Little Ice Age to the present using a lidar-based high-resolution glacier inventory in Austria, The Cryosphere, 9, 753-766, doi:10.5194/tc-9-753-2015, 2015.

Hock, R.: A distributed temperature-index ice- and snowmelt model including potential direct solar radiation, J. Glaciol., 45, 101111, 1999.

Huttenlau, M., Bellinger, J., Schattan, P., Förster, K., Oesterle, F., Schneider, K., Achleitner, S., Schöber, J., Raffeiner, G., and Kirnbauer, R.: Flood forecasting system for the Tyrolean Inn River (Austria): current state and further enhancements of a modular forecasting system for alpine catchments, in: Living with natural risks, 13th Congress INTERPRAEVENT 2016, Lucerne, 909-916, International Research Society INTERPRAEVENT, Klagenfurt, Austria, 2016.

Kanamitsu, M., Kumar, A., Juang, H.-M. H., Schemm, J.-K., Wang, W., Yang, F., Hong, S.-Y., Peng, P., Chen, W., Moorthi, S., and Ji, M.: NCEP Dynamical Seasonal Forecast System 
2000, B. Am. Meteorol. Soc., 83, 1019-1037, doi:10.1175/15200477(2002)083<1019:NDSFS>2.3.CO;2, 2002.

Klemeš, V.: Operational testing of hydrological simulation models, Hydrolog. Sci. J., 31, 13-24, doi:10.1080/02626668609491024, 1986.

Klemeš, V.: The modelling of mountain hydrology: the ultimate challenge, in: Hydrology of mountainous areas, edited by: Molnár, L., 29-43, International Association of Hydrological Sciences, Wallingford, 1990.

Koboltschnig, G. R. and Schöner, W.: The relevance of glacier melt in the water cycle of the Alps: the example of Austria, Hydrol. Earth Syst. Sci., 15, 2039-2048, doi:10.5194/hess-15-20392011, 2011.

Kuentz, A., Mathevet, T., Gailhard, J., and Hingray, B.: Building long-term and high spatio-temporal resolution precipitation and air temperature reanalyses by mixing local observations and global atmospheric reanalyses: the ANATEM model, Hydrol. Earth Syst. Sci., 19, 2717-2736, doi:10.5194/hess-19-27172015, 2015.

Marzeion, B., Cogley, J. G., Richter, K., and Parkes, D.: Glaciers. Attribution of global glacier mass loss to anthropogenic and natural causes, Science, 345, 919-921, doi:10.1126/science.1254702, 2014.

McCabe, G. J. and Markstrom, S. L.: A Monthly Water-Balance Model Driven By a Graphical User Interface, U.S. Geological Survey Open-File report, 2007.

Moriasi, D. N., Arnold, J. G., van Liew, M. W., Bingner, R. L., Harmel, R. D., and Veith, T. L.: Model evaluation guidelines for systematic quantification of accuracy in watershed simulations, Trans. ASABE, 50, 885-900, 2007.

Rango, A. and Martinec, J.: Revisting the degree-day method for snowmelt computations, J. Am. Water Resour. Assoc., 31, 657669, doi:10.1111/j.1752-1688.1995.tb03392.x, 1995.

Saha, S., Moorthi, S., Pan, H.-L., Wu, X., Wang, J., Nadiga, S., Tripp, P., Kistler, R., Woollen, J., Behringer, D., Liu, H., Stokes, D., Grumbine, R., Gayno, G., Wang, J., Hou, Y.-T., Chuang, H.Y., Juang, H.-M. H., Sela, J., Iredell, M., Treadon, R., Kleist, D., Van Delst, P., Keyser, D., Derber, J., Ek, M., Meng, J., Wei, H., Yang, R., Lord, S., Van Den Dool, H., Kumar, A., Wang, W., Long, C., Chelliah, M., Xue, Y., Huang, B., Schemm, J.-K., Ebisuzaki, W., Lin, R., Xie, P., Chen, M., Zhou, S., Higgins, W., Zou, C.-Z., Liu, Q., Chen, Y., Han, Y., Cucurull, L., Reynolds, R. W., Rutledge, G., and Goldberg, M.: The NCEP Climate Forecast System Reanalysis, B. Am. Meteorol. Soc., 91, 1015-1057, doi:10.1175/2010BAMS3001.1, 2010.
Saha, S., Moorthi, S., Wu, X., Wang, J., Nadiga, S., Tripp, P., Behringer, D., Hou, Y.-T., Chuang, H.-Y., Iredell, M., Ek, M., Meng, J., Yang, R., Mendez, M. P., van den Dool, H., Zhang, Q., Wang, W., Chen, M., and Becker, E.: The NCEP Climate Forecast System Version 2, J. Climate, 27, 2185-2208, doi:10.1175/JCLI-D-12-00823.1, 2014.

Schaefli, B.: Projecting hydropower production under future climates: a guide for decision-makers and modelers to interpret and design climate change impact assessments, WIREs Water, 2, 271-289, doi:10.1002/wat2.1083, 2015.

Schueller, F., Förster, K., Hanzer, F., Huttenlau, M., Marzeion, B., Strasser, U., Achleitner, S., and Kirnbauer, R.: Multiscale Snow/Icemelt Discharge Simulations into Alpine Reservoirs: adding Glacier Dynamics to a Hydrological Model, Geophysical Research Abstracts, p. 3244, 2015.

Strasser, U.: Modelling of the mountain snow cover in the Berchtesgaden National Park, vol. 55 of Berchtesgaden National Park research report, Nationalparkverwaltung Berchtesgaden, Berchtesgaden, 2008.

Strasser, U., Warscher, M., and Liston, G. E.: Modeling SnowCanopy Processes on an Idealized Mountain, J. Hydrometeor., 12, 663-677, doi:10.1175/2011JHM1344.1, 2011.

Thornthwaite, C. W.: An Approach toward a Rational Classification of Climate, Geogr. Rev., 38, 55-94, doi:10.2307/210739, 1948.

Viviroli, D., Dürr, H. H., Messerli, B., Meybeck, M., and Weingartner, R.: Mountains of the world, water towers for humanity, Water Resour. Res., 43, 1-13, W07447, doi:10.1029/2006WR005653, 2007.

Wood, A. W., Maurer, E. P., Kumar, A., and Lettenmaier, D. P.: Long-range experimental hydrologic forecasting for the eastern United States, J. Geophys. Res., 107, 4429 (1-16), doi:10.1029/2001JD000659, 2002.

Yuan, X., Wood, E. F., Luo, L., and Pan, M.: A first look at Climate Forecast System version 2 (CFSv2) for hydrological seasonal prediction, Geophys. Res. Lett., 38, 1-7, L13402, doi:10.1029/2011GL047792, 2011.

Yuan, X., Wood, E. F., and Ma, Z.: A review on climatemodel-based seasonal hydrologic forecasting: Physical understanding and system development, WIREs Water, 2, 523-536, doi:10.1002/wat2.1088, 2015. 